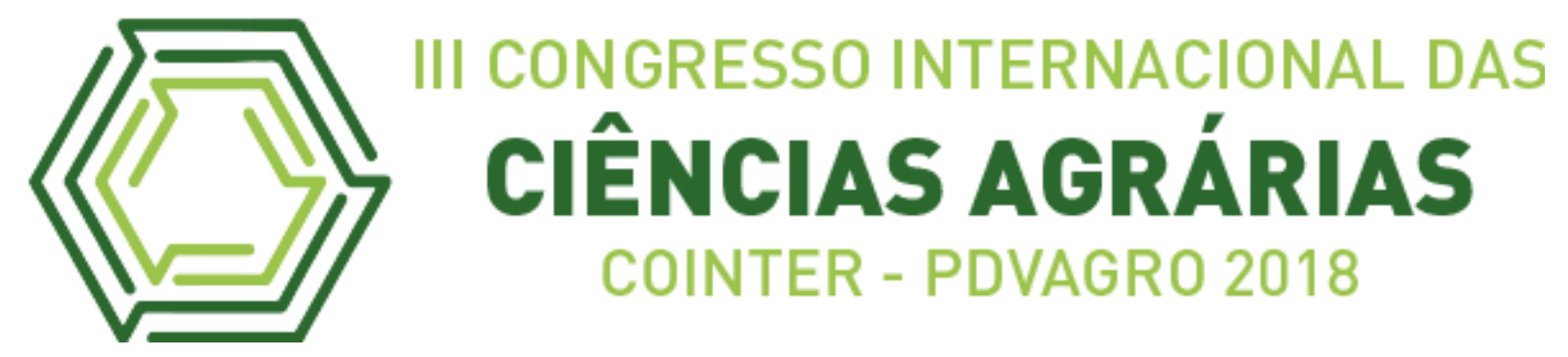

\title{
O MANEJO DO SOLO NA PRODUÇÃO DE MUDAS: DIÁLOGO ENTRE PEDOLOGIA, AGROECOLOGIA E EXTENSÃO RURAL
}

\section{THE MANAGEMENT OF SOIL IN THE PRODUCTION OF CHANGES: DIALOGUE BETWEEN PEDOLOGY, AGROECOLOGY AND RURAL EXTENSION}

Apresentação: Relato de Experiência

Amanda Lima de Sena ${ }^{1}$; Izis Tainã Freire Alves ${ }^{2}$; Diana da Silva Santos ${ }^{3}$; Gabriel

Santos de Jesus ${ }^{4}$; Tainã Cádija A. de Mamede ${ }^{5}$

\section{DOI: https://doi.org/10.31692/2526-7701.IIICOINTERPDVAGRO.2018.00753}

\section{Introdução}

Este trabalho constitui em descrever o cotidiano de um agricultor rural em relação ao manejo do solo para a produção de mudas diversificadas. Para tal, uma prática de campo foi realizada em Amélia Rodrigues, Bahia pelos discentes da disciplina Pedologia do curso de Agronomia da Universidade Estadual de Feira de Santana - UEFS, onde foi aplicada uma entrevista semiestruturada. Após coleta dos dados, foi possível perceber as técnicas agrícolas que são adotadas pelo produtor que estão aliadas a agricultura familiar e a princípios agroecológicos, podendo vir a ser aprimoradas a partir de uma educação em solos que valorize a união do conhecimento empírico e científico.

\section{Relato de Experiência}

Poucos setores da economia brasileira têm desenvolvido tanto como a agricultura. Observa-se que a produtividade de algumas culturas vem aumentando substancialmente, mesmo em áreas anteriormente tidas como improprias à exploração agrícola. Isto indica que o conhecimento a respeito dos recursos de solos deve ser cada vez mais intensificado, visando assim atender a programas de adubação, correção, manejo e conservação, qualidade do solo, agricultura de precisão, dentre outros (KER \& NOVAIS, 2003). A agricultura familiar ainda é

\footnotetext{
${ }^{1}$ Agronomia, Universidade Estadual de Feira de Santana, sena_amanda@outlook.co

${ }^{2}$ Agronomia, Universidade Estadual de Feira de Santana, izistaina@outlook.com

${ }^{3}$ Agronomia, Universidade Estadual de Feira de Santana, dianaagro@hotmail.com

${ }^{4}$ Agronomia, Universidade Estadual de Feira de Santana, santosgabriel96@hotmail.com

${ }^{5}$ Professora Orientadora, Universidade Estadual de Feira de Santana, tai_bio@yahoo.com.br
} 
a forma preponderante de produção agrícola em várias áreas do país, sendo o principal agente propulsor do desenvolvimento comercial e se devidamente apoiada por políticas públicas e iniciativas locais, pode se transformar na grande potencializadora de um desenvolvimento descentralizado e voltado para uma perspectiva de sustentabilidade, onde a agroecologia pode ganhar seu papel, valorizando assim, sementes tradicionais e promovendo a harmonia com a natureza e cultura local (SANTOS, 2001). Os produtores rurais apresentam conhecimentos próprios sobre o solo que utilizam, possuindo uma maneira particular de classifica-lo. Empregam uma terminologia, desenvolvida em função da observação de feições morfológicas e do seu funcionamento, apropriando em um conjunto de conhecimentos acumulados sobre os mesmos, ao longo de gerações (BENASSI, 2008).

A pesquisa foi realizada no dia 23 de abril de 2016, utilizaram-se dados primários e secundários para elaboração do diagnóstico. Foi elaborada uma entrevista semiestruturada que teve como objetivo avaliar o conhecimento do produtor e as técnicas utilizadas para melhoramento do solo e consequentemente a produção de mudas. A entrevista foi realizada com um dos agricultores da comunidade Quatro Estradas, localizada nas proximidades do Centro Agroecológico Rio Seco, município de Amélia Rodrigues-BA. A entrevista teve como base os seguintes tópicos: Manejo do solo; Herança familiar; Irrigação; Morfologia do solo.

A principal atividade realizada na propriedade se refere à produção de mudas frutíferas e ornamentais. Dentre estas se destacam, Citrus sp (laranja); Malpighia emarginata (acerola); Caesalpinia echinata (pau-brasil); Cocos nucifera (coqueiro). Percebe-se a produção de mudas de espécies florestais nativas, ameaçada de extinção e que podem ser utilizadas para recuperação de áreas degradadas, a saber, Caesalpinia echinata (pau-brasil) (Figura 1A). 

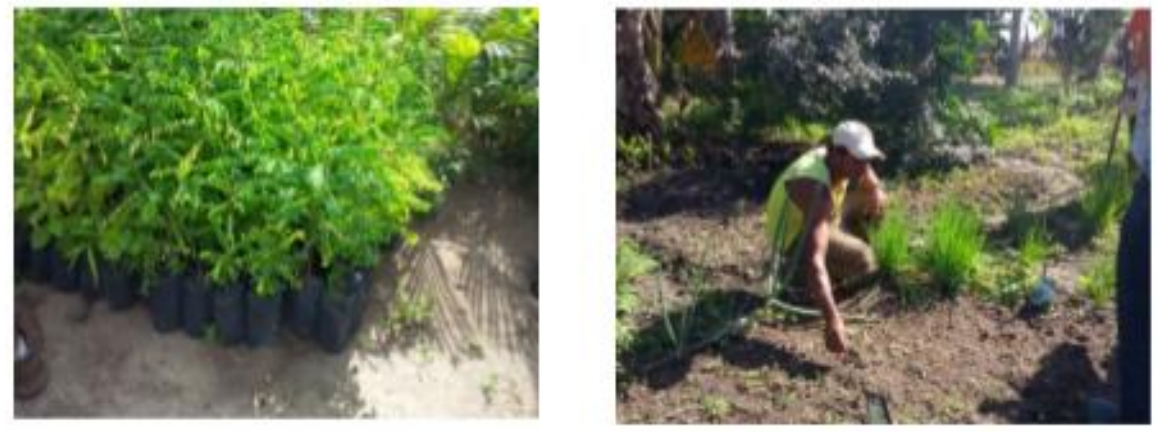

Figura 1 - (A) Muda da espécie Caesalpinia echinata (pau-brasil); (B) Hortaliças.

\section{Imagem própria}

A espécie já foi estudo para modelo de reintrodução em fragmentos naturais da Mata Atlântica em locais ao norte da Bahia (MMA, 2018), sendo de grande valor econômico, cultural e ambiental. O produtor também cultiva diversas hortaliças (Figura 1B).

Segundo o produtor a sua 'terra' apresenta potencial para atividade agrícola. Esta observação foi feita por ele segundo o critério de identificação da presença de dois tipos de solo no local, descrito como "barro vermelho" (a seu ver com boa retenção de agua e pouca matéria orgânica) e "terra preta" (muita matéria orgânica e pouca retenção de água). No mapa de solos do município de Amélia Rodrigues-BA observa-se a predominância de dois solos: Argissolo Vermelho Amarelo e Vertissolo (EMBRAPA, 1973).

Vale salientar que o conhecimento do produtor em relação ao solo tem significado na herança tradicional, um dos princípios agroecológicos. A agroecologia pode ser considerada uma ciência em construção, pois incorpora o conhecimento tradicional que por definição não é científico (GUZMÁN, 2002; EMBRAPA, 2008).

A fim de adubar a terra para produção de mudas, o agricultor detém de algumas técnicas, dentre elas a compostagem, feita por ele somente com folhas e galhos secos. Os materiais vegetais frescos e verdes tendem a ser mais ricos em nitrogênio, se comparados aos materiais secos, assim como estrumes e urinas de animais (OLIVEIRA et al., 2008). O mesmo faz uso também de urina de vaca diluída com a finalidade de adubação do solo e pulverização das plantas. O composto da urina é muito rico em fenóis, substancia que aumenta a resistência contra as pragas, além de permitir um aumento do grau de brix (quantidade de açúcar presente na polpa) (PESAGRO-RIO, 2002). 
O produtor também realiza queimada de materiais na propriedade e utiliza as cinzas como adubo. As cinzas vegetais podem favorecer o desenvolvimento das plantas, pois contêm cálcio, magnésio, fósforo e outros elementos que são micronutrientes essenciais para sua nutrição (Brady, 2009) porem o agricultor não utiliza apenas de espécies vegetais na queimada, fazendo uso também dos resíduos sólidos (orgânico e inorgânico) com exceção do plástico. Além disso, realiza o processo de queimada sempre no mesmo lugar, o que pode vir em longo prazo trazer danos ao solo, eliminando nutrientes essenciais as plantas. Sobre a utilização de adubo químico, o mesmo alega que por vezes faz uso de NPK para que as mudas fiquem mais vistosas para o consumidor. De acordo com a Rede Ecovida para que a produção seja considerada agroecológica se faz necessário a não utilização de agrotóxicos, adubos químicos e OGMs na produção (ECOVIDA, 2002). Grande parte das mudas produzidas pelo agricultor passa pelo processo de enxertia. O mesmo realiza tal procedimento com a finalidade de garantir as mudas maior resistência, uma vez que terão que se adaptar aos variados tipos de solo, desde aquele rico em nutrientes a outro com déficit, assim como a resistir possíveis pragas. A enxertia pode ser considerada uma técnica com princípios agroecológicos, uma vez que diminui os danos ambientais e econômicos causados pelo ataque de insetos, pragas e doenças (EMBRAPA, 2015; CARDOSO et al., 2015).

Vale ressaltar que as mudas são produzidas no quintal da residência do agricultor, não possuindo o mesmo incentivo governamental. O mesmo alegou não ser organizado para tal, tampouco possui inscrição em alguma entidade de classe.

\section{Considerações}

O manejo do solo pelo agricultor pode vir a trazer maiores alternativas agroecológicas se assistido pela Universidade Estadual de Feira de Santana, assim como, o Centro Agroecológico Rio Seco, os quais promoveriam uma Educação em solos de forma a conciliar o saber popular e científico. Além disso, uma atividade extensionista aproxima de forma singular os estudantes de agronomia da realidade rural e da agricultura familiar.

\section{Referências}


ALVES, A. G. C.; MARQUES, J.G.W.; SILVA, I.F.; QUEIROZ, S. B.; RIBEIRO, M. R. Caracterização etnopedológica de Planossolos utilizados em cerâmica artesanal no Agreste Paraibano. Rev. Bras. de Ciências do Solo, v. 3, p. 379-388, 2005.

BASHER, L.R. Is pedology dead and buried? J. Soil Res., v. 35, p. 979-994, 1997.

BOULET, R. Análise estrutural da cobertura pedológica e cartografia. In: Congresso Brasileiro de Ciência do Solo, 25., Campinas, 1988. Anais. Campinas, Sociedade Brasileira de Ciência do Solo,. p.79-90, 1988. 